Article

\title{
Data-Driven Approach to Understand the Mobility Patterns of the Portuguese Population during the COVID-19 Pandemic
}

\author{
Tiago Tamagusko (1) and Adelino Ferreira *(i) \\ Research Center for Territory, Transports and Environment, Department of Civil Engineering, \\ University of Coimbra, 3030-788 Coimbra, Portugal; tamagusko@gmail.com \\ * Correspondence: adelino@dec.uc.pt; Tel.: +351-239-79-7101
}

Received: 14 October 2020; Accepted: 20 November 2020; Published: 23 November 2020

\begin{abstract}
SARS-CoV-2 emerged in late 2019. Since then, it has spread to several countries, becoming classified as a pandemic. So far, there is no definitive treatment or vaccine, so the best solution is to prevent transmission between individuals through social distancing. However, it is not easy to measure the effectiveness of these distance measures. Therefore, this study uses data from Google COVID-19 Community Mobility Reports to understand the Portuguese population's mobility patterns during the COVID-19 pandemic. In this study, the Rt value was modeled for Portugal. In addition, the changepoint was calculated for the population mobility patterns. Thus, the mobility pattern change was used to understand the impact of social distance measures on the dissemination of COVID-19. As a result, it can be stated that the initial $R t$ value in Portugal was very close to 3 , falling to values close to 1 after 25 days. Social isolation measures were adopted quickly. Furthermore, it was observed that public transport was avoided during the pandemic. Finally, until the emergence of a vaccine or an effective treatment, this is the new normal, and it must be understood that new patterns of mobility, social interaction, and hygiene must be adapted to this reality.
\end{abstract}

Keywords: COVID-19; mobility patterns; Rt; changepoint; modeling; Portugal

\section{Introduction}

At the end of 2019, the new Coronavirus (SARS-CoV-2) appeared in the province of Wuhan (China) [1], causing cases of a disease named COVID-19 to occur [2]. To combat COVID-19, China adopted the lockdown of this province on 23 January [3]. This disease spread rapidly to other countries, with the first cases reported in Europe in the second half of January [4]. Concerning Portugal, the first confirmed case of COVID-19 was on 3 March, 2020 [5], since the Portuguese government has adopted a series of measures to control the pandemic. To date, there are no vaccines for this disease, so the best strategy to combat COVID-19 is to prevent its transmission through social distancing. However, this is not a simple task, since many social activities are based on contact with people and mobility. In the specific case of the transmission of COVID-19, the ideal scenario would be to monitor people's contacts. Initiatives in this direction have been developed, but they face some concerns related to privacy. Another possibility is to measure the likelihood of contacts; this approach can be made by measuring people's concentration in certain places. Thus, the population's mobility patterns may indicate the degree of adoption of social distancing [6]. As a way of assessing the spread of the pandemic, this study used the effective reproduction number $(R t)$, a value that represents the average number of secondary cases per infected case at time $t$ [7-9].

Nevertheless, effectively monitoring population mobility is a difficult task for governments. Google recently released the global time-limited sharing of mobility data [10]. This report presents 
several statistics and aims to promote studies that can help combat COVID-19. Mobility data are divided into six categories: retail and recreation; grocery and pharmacy; parks; transit stations; workplace; and residential. The values presented are percentage changes to normal (baseline) mobility patterns. Currently, most European countries face the challenge of reactivating their economies; this task is linked to the gradual re-opening of services, public communal areas, and public transport. However, it is still not fully understood how the population has adopted the lockdown measures. In this sense, this paper finds relationships between the mobility patterns, the social distancing measures adopted, and the spread of the disease in Portugal.

Recent studies show that mobility patterns can considerably change contagion risk, with maintaining work on-site during the pandemic crisis being the factor identified as having the most significant risk [11]. Based on this result, it can be said that the change in the population's habits plays a significant role in the spread of COVID-19 in the community.

This research used exploratory data analysis to provide insights into the Portuguese population's mobility patterns during the COVID-19 pandemic. So far, 2694 (deaths confirmed in Portugal until 4 November 2020) deaths in Portugal have been confirmed [12], and a second wave is starting. We hope that this study will contribute to the choice of better public policies to combat this pandemic.

\section{Materials and Methods}

\subsection{Events}

In response to the COVID-19 crisis in Portugal, the government adopted several measures to mitigate the disease's spread. The main measures are grouped in Table 1. Other measures were adopted, but these events were considered more relevant.

Table 1. Main public policies to mitigate the spread of COVID-19 in Portugal $[5,13]$.

\begin{tabular}{ccc}
\hline Intervention & Description & Date \\
\hline Public events & Gatherings with more than 100 people are forbidden. & 12 March 2020 \\
\hline Social distancing & $\begin{array}{c}\text { Capacity restrictions in bars and restaurants, closed } \\
\text { night clubs, limiting people in closed spaces } \\
\text { are recommended. }\end{array}$ & 12 March 2020 \\
\hline Schools and universities & Schools and universities closed. & 14 March 2020 \\
\hline Social distancing & $\begin{array}{c}\text { Decrease in capacity to 1/3 and maintain a minimum } \\
\text { distance of 1 m (ideally 2 m) in public services. }\end{array}$ & 17 March 2020 \\
\hline Self-isolating of ill people & $\begin{array}{c}\text { Isolation is mandatory for sick people or being } \\
\text { monitored by health authorities. }\end{array}$ & 19 March 2020 \\
\hline Lockdown start & Start of the lockdown. & 22 March 2020 \\
\hline Public gatherings & Gatherings of more than five people prohibited \\
(except for large families). & 2 April 2020 \\
\hline Lockdown end & End of the lockdown. & 3 May 2020 \\
\hline
\end{tabular}

\subsection{Data}

To develop this study, mobility data [10] and the cases of COVID-19 in Portugal [14] were considered. The mobility report, called Google COVID-19 Community Mobility Reports, is data collected from mobile devices to quantify people's movement during the pandemic. These values are anonymized and aggregated based on Google's algorithm, and the artificial noise sample is added to ensure that no individual can be identified based on their location information [15]. The report shows how the population moves and how long they stay in different locations (Table 2). 
Table 2. Report categories [10].

\begin{tabular}{|c|c|}
\hline Category & Subcategories \\
\hline Retail and recreation & $\begin{array}{l}\text { Restaurants, cafes, shopping centers, theme parks, museums, libraries, } \\
\text { and movie theaters. }\end{array}$ \\
\hline Grocery and pharmacy & $\begin{array}{c}\text { Grocery markets, food warehouses, farmers markets, specialty food shops, } \\
\text { drug stores, and pharmacies. }\end{array}$ \\
\hline Parks & $\begin{array}{c}\text { National parks, public beaches, marinas, dog parks, plazas, } \\
\text { and public gardens. }\end{array}$ \\
\hline Transit stations & Public transport hubs such as subway, bus, and train stations. \\
\hline Workplace & Places of work. \\
\hline Residential & Places of residence. \\
\hline
\end{tabular}

The values presented for the categories are related to a baseline, which corresponds to the week (from 3 January to 6 February 2020). With these parameters, it is possible to assess the population's adherence to the social isolation measures enacted by the government. The daily variation of values over time in Portugal, from 15 February to 30 October, is shown in Figures 1 and 2.
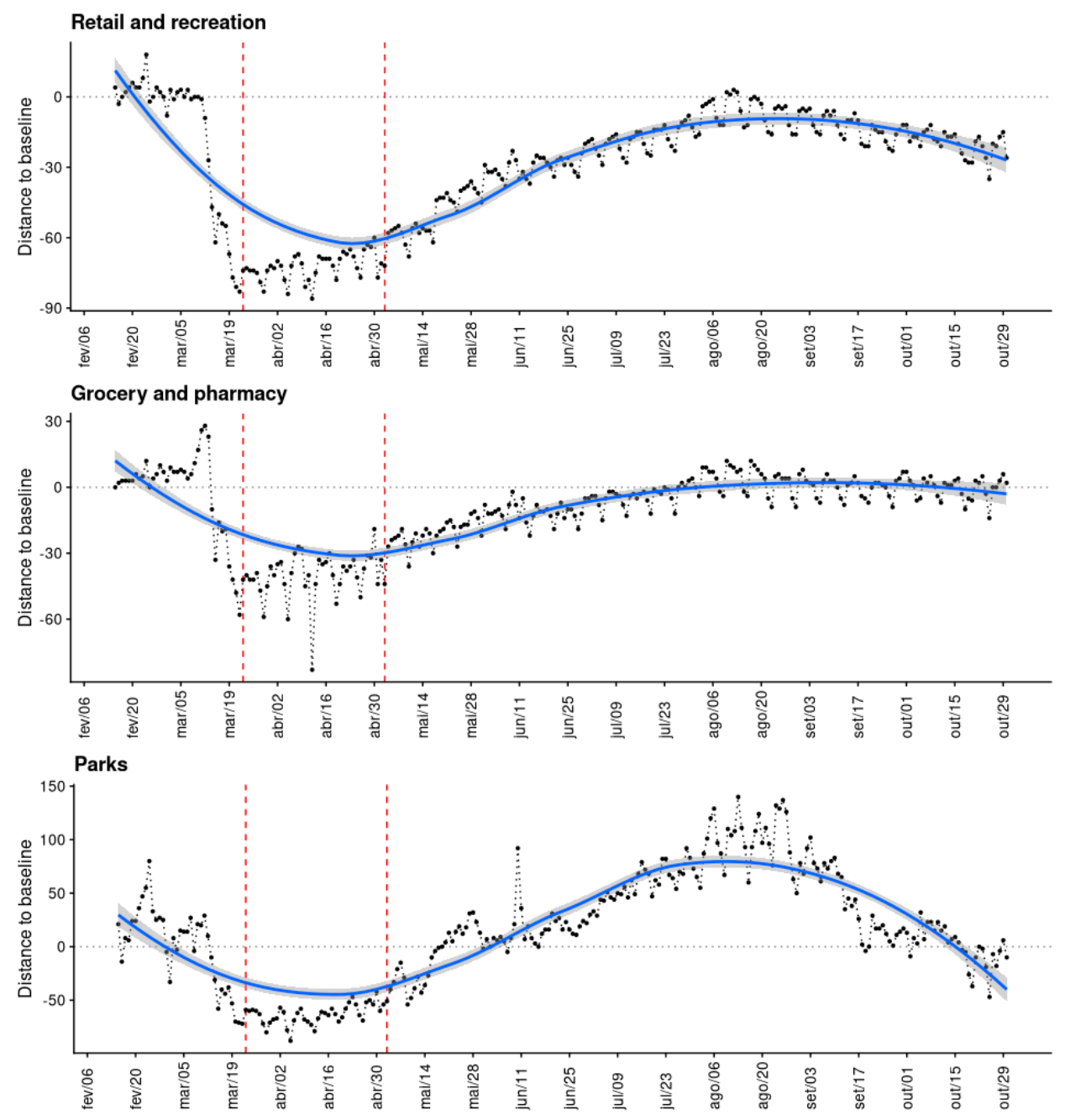

Figure 1. Mobility trends for the retail and recreation, grocery and pharmacy, and parks categories in Portugal. 
In these graphs, the vertical axis represents the distance to the baseline. The area between red dashed lines represents Portugal's lockdown period (started on 22 March and finished on 3 May).
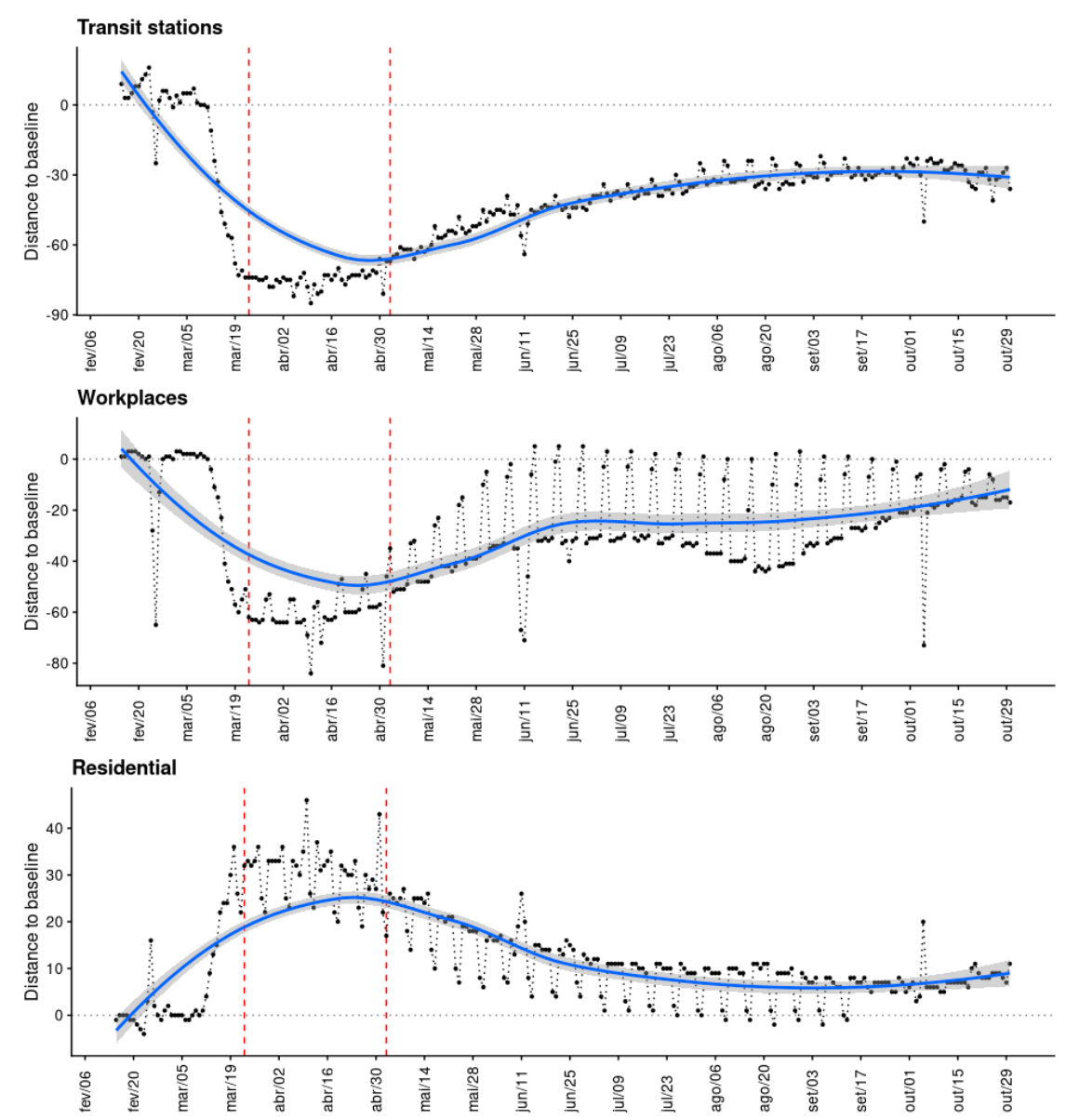

Figure 2. Mobility trends for the transit stations, workplaces, and residential categories in Portugal.

According to the data provided even before the lockdown, the first five categories' values show falls. There was growth only in the residential category. In the days before the lockdown, there are peaks in the items grocery and pharmacy; this can be explained by the general rush to get supplies. The park-related peaks do not have a simple explanation. However, after this brief initial period, the population followed the imposed recommendations avoiding these locations during the lockdown.

After the softening of the measures, there is an increasing demand (over $100 \%$ at the end of August) for parks. It is assumed that this was due to the influence of the adaptation of the population's routines to outdoor activities. Additionally, it is observed that after the increase in the number of cases, and with the prospect of a second wave of COVID-19, the population is again attending parks less, mainly from the middle of September. This drop could be related to the end of the August vacation period; however, it is quite pronounced and coincides with the increase in the number of COVID-19 cases. Finally, it is impossible to reach definitive conclusions in this sense due to the lack of annualized data.

It should also be noted that before 22 March, schools and universities were closed, and several companies started to operate in teleworking. After lockdown, the values remained historically low. As expected, the tendency to stay at home is highly related to the workplace, in an approximately reversed trend. The low levels of public transport use are viewed with concern; however, this is due to the population's perception of lack of safety in these places. According to [11], public transport is a significant risk of contagion, mainly in large equipment such as the metro. This opens the discussion about the possibility of adopting measures to effectively control access to public transport equipment. 
Likewise, studies conducted with public transport users in Sweden's most populous regions found values to decrease between 40 and $60 \%$ during this pandemic. The type of confinement imposed in this Scandinavian country was very different from that applied in Portugal (less restrictive) [16]. However, the pattern of avoiding public transport has similar levels.

In addition to the mobility data, values related to the cases of COVID-19 in Portugal were used between 3 March (first confirmed case) and 3 November (Figure 3). It is observed that the notification of the number of new cases is somewhat irregular. On weekends and holidays, the notifications are lower, and the following notifications are "inflated". Another problem observed is that the number of confirmed cases is proportional to the number of tests performed. Therefore, the procedures adopted for testing the population influence the results of $R t$ in this study. Appendix B presents the resources used to develop these data.

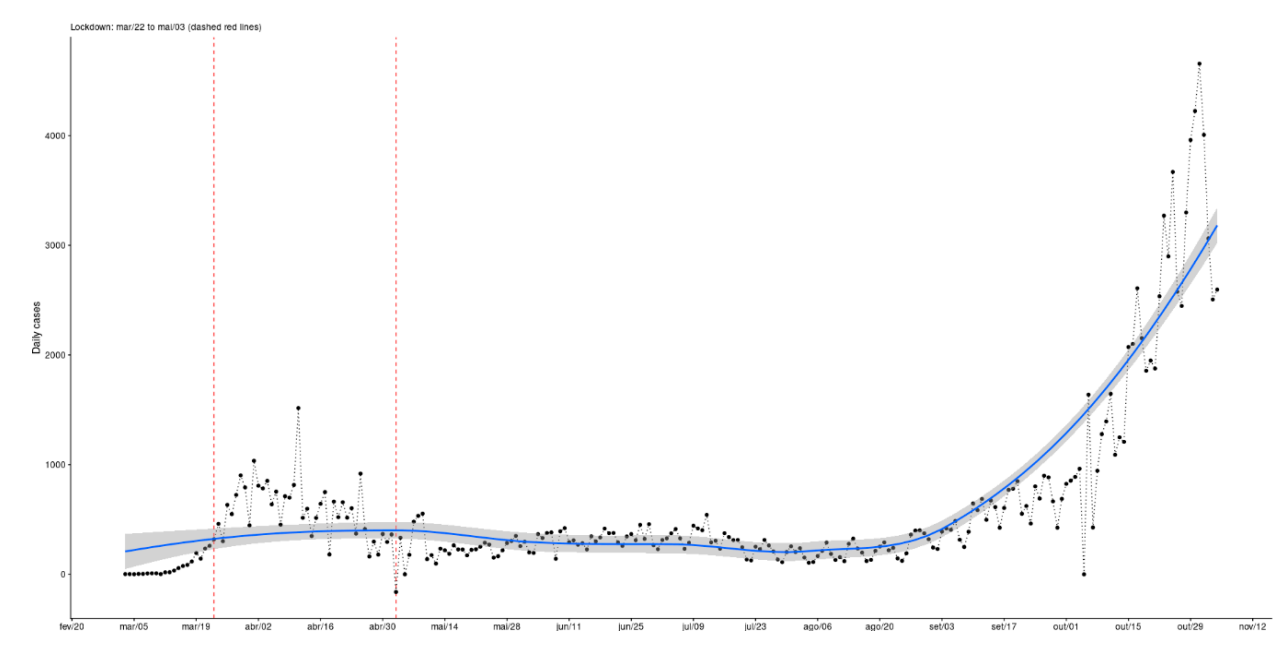

Figure 3. Cases of COVID-19 in Portugal.

\subsection{Methods}

This study's idea is that $R t$ can be influenced by the number of contacts between infected and susceptible individuals. Therefore, the social distancing measures adopted by the public authorities can influence this risk factor. In this study, the contact rate is approximated by the population's mobility patterns during the pandemic period. Thus, it is considered that if the population decreases its presence in parks, restaurants, transportation stations, among others, the number of contacts decreases.

Supported by the R programming language $[17,18]$, the Changepoint framework [19] was used to detect changing mobility values over time. Thus, it was possible to determine (approximately) the day when the mobility values changed their trend. Therefore, the goal is to detect the changepoint from the time series of mobility data provided. In this study, the mean approach was used, with the BINSEG (Binary Segmentation) method $[19,20]$ to detect changepoints from the mobility patterns sample. The Binary Segmentation method consists of calculating a single changepoint method for the entire dataset. If a changepoint is found, this dataset is divided into two subsets, and the changepoint is recalculated again for each subset $[20,21]$. This process is performed iteratively until the model parameters are satisfied. This method was also configured to search up to a maximum of two changepoints in the sample under analysis.

Another objective of this study is to calculate the $R t$ in Portugal, a developed task with support from the $R$ and the EpiEstim framework [9]. Rt is the average number of secondary cases that each infected individual would infect if conditions remained as they were at time $t$ [7-9]. Thus, the value of $R t$ is determined according to Equation (1) [9].

$$
R(t)=\sum_{s=1}^{t} I_{t-s} w s,
$$


where $I$ is the number of people infected at any given time, and ws corresponds to the probability of infection distribution. This distribution depends on the characteristics of the disease. So, to determine the $w s$, the method adopted was non-parametric serial interval (SI). We used the serial interval (SI) parameters presented by Nishiura et al. [22], with $\mu=4.6$ days (median serial interval) and $\sigma=2.9$ days (standard deviation).

Therefore, according to the study mentioned before [22], the average time for infected people to generate a second infection is 4.6 days. However, COVID-19 does not present itself equally in all infected individuals, they can be infectious over a period (serial interval). Consequently, it is expected that an individual exposed to COVID-19 may be infected and have an infectious window that lasts up to 14 days. This is the concept that endorses the WHO's 14-day quarantine recommendation [23].

Finally, $R t$ is an important indicator, as it can identify the stage of an infectious disease. For example, an $R t$ of 2 means that each infected person, on average, transmits the disease to two other people. On the other hand, an $R t$ less than 1 indicates that the disease's spread is controlled and tends to disappear $[7,8]$.

\section{Results}

The first result to be presented is the estimated day for a change in the Portuguese population (Figures 4 and 5). The data range is from 15 February to 30 October.
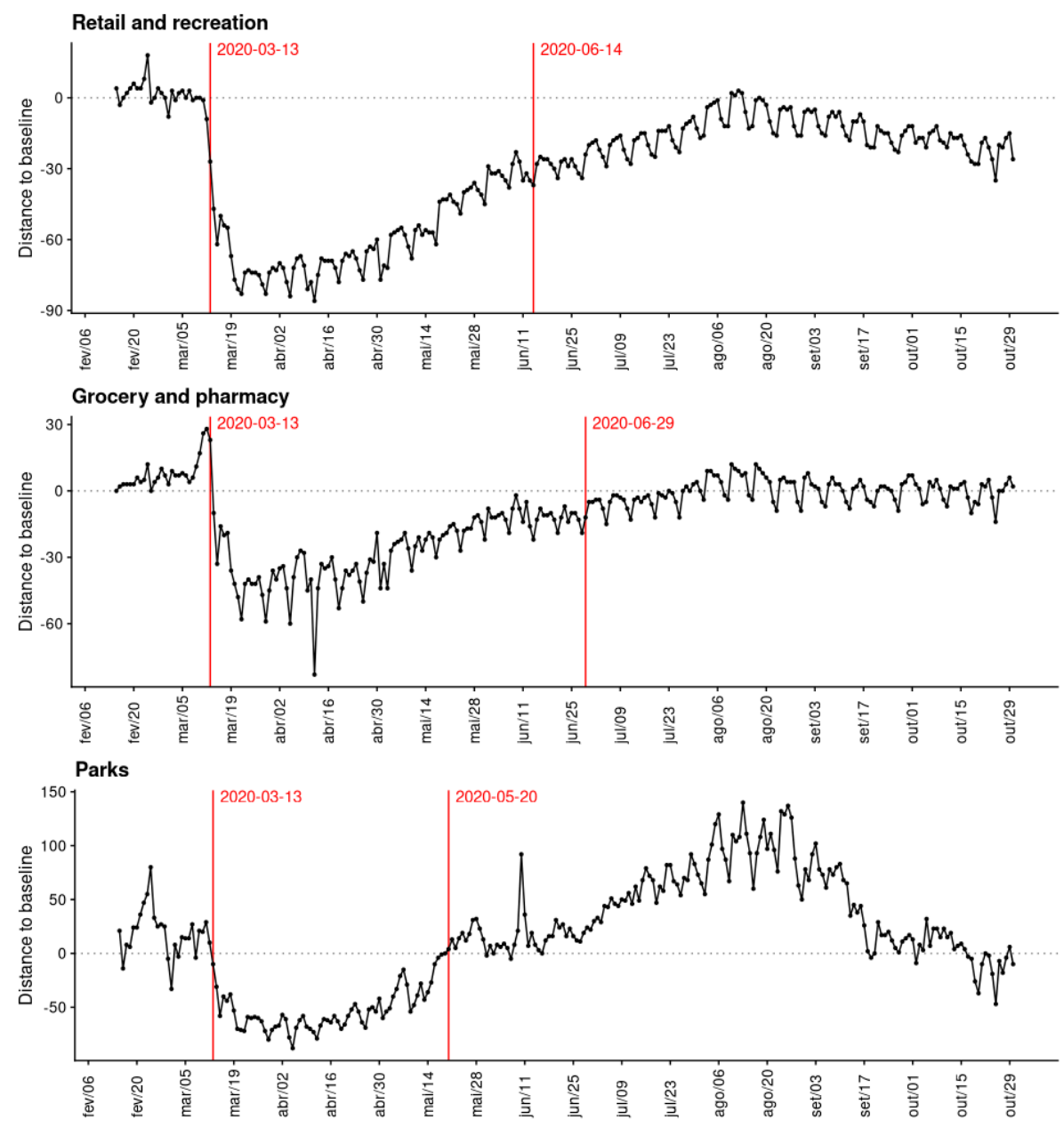

Figure 4. Changepoint for the retail and recreation, grocery and pharmacy, and parks categories in Portugal. 
As presented before, these values were calculated using the Changepoint framework [19] and based on the daily values for mobility data in Portugal [10]. The first approximate changepoint is between the 12 and the 14 March. Still, it is observed that the most significant drop occurs from 12 March, which is the date when the first public measures of social distancing were adopted. Thus, from the moment the government recommended people to stay at home, avoid public places, and maintain social distance, the population's mobility pattern fell rapidly. In addition, due to the characteristics of COVID-19, the number of new cases took time to slow down.
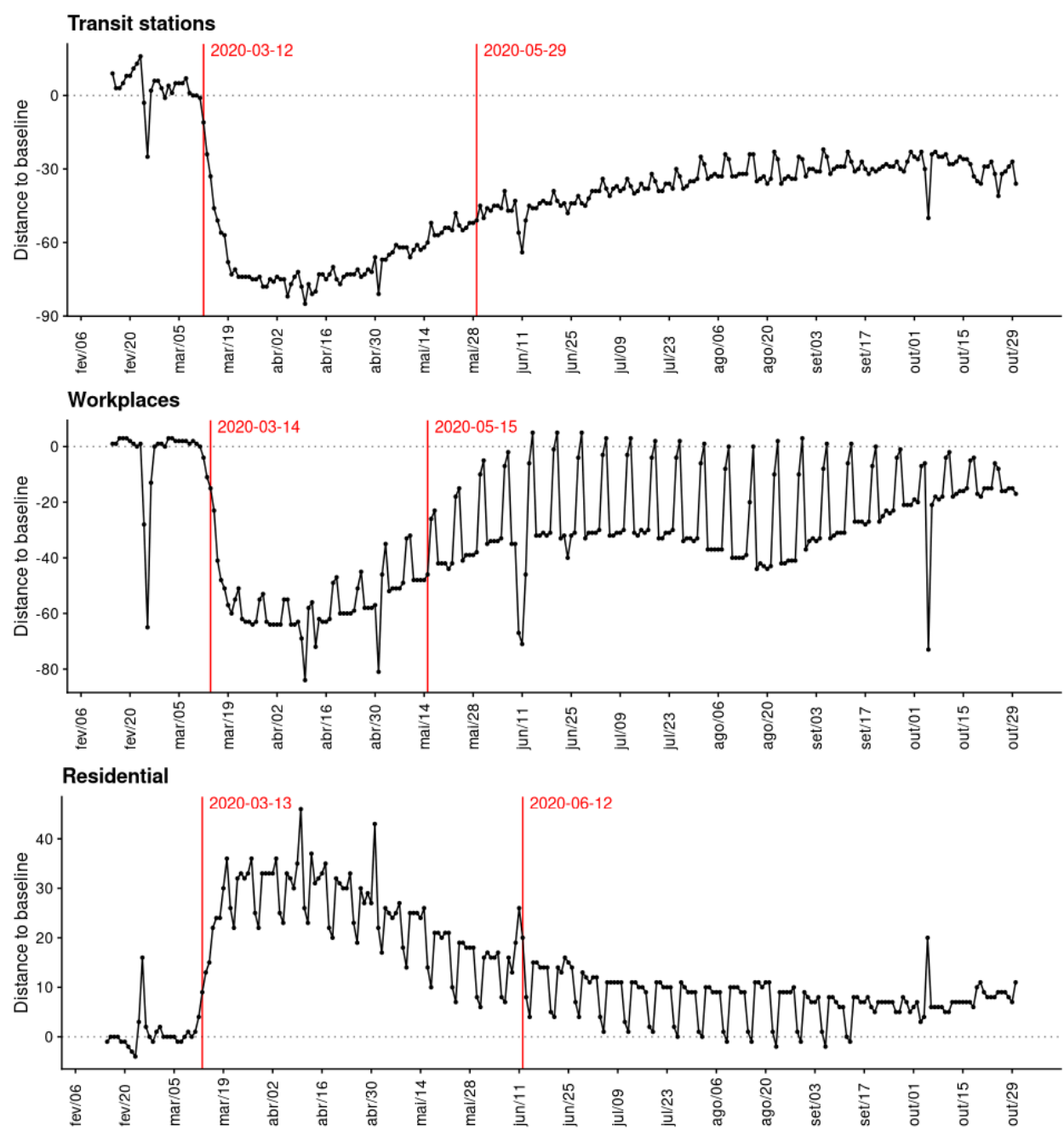

Figure 5. Changepoint for the retail and recreation, grocery and pharmacy, and parks categories in Portugal.

The second changepoint is not as evident as the first one, and may vary according to the statistical method adopted. This second changepoint represents the point at which the population started to resume activities. The first activity resumed was the workplaces, which changed on May 15th, followed by the parks on 20 May, and the transit stations on 29 May. At this point, one can imagine that the population's first objective after the most severe lockdown was the resumption of economic activities. Another interesting point worth mentioning is that the parks' changepoint occurred approximately on the baseline on 20 May. This shows that after the relaxation of the confinement measures, the population sought outdoor activities.

The first case of COVID-19 in Portugal was on 3 March, however, the first calculated $R t$ value is from 10 March. Therefore, these first seven days are used by EpiEstim to calculate $R_{0}$. Another observation is that the $95 \%$ confidence interval (a grey area in the graph) is wide at the beginning of 
Portugal's pandemic. The result of the Rt value, based on epidemiological modeling developed for the COVID-19 pandemic in Portugal, calculated between 10 March and 3 November, is shown in Figure 6. The result of the epidemiological modeling is presented in Appendix A.

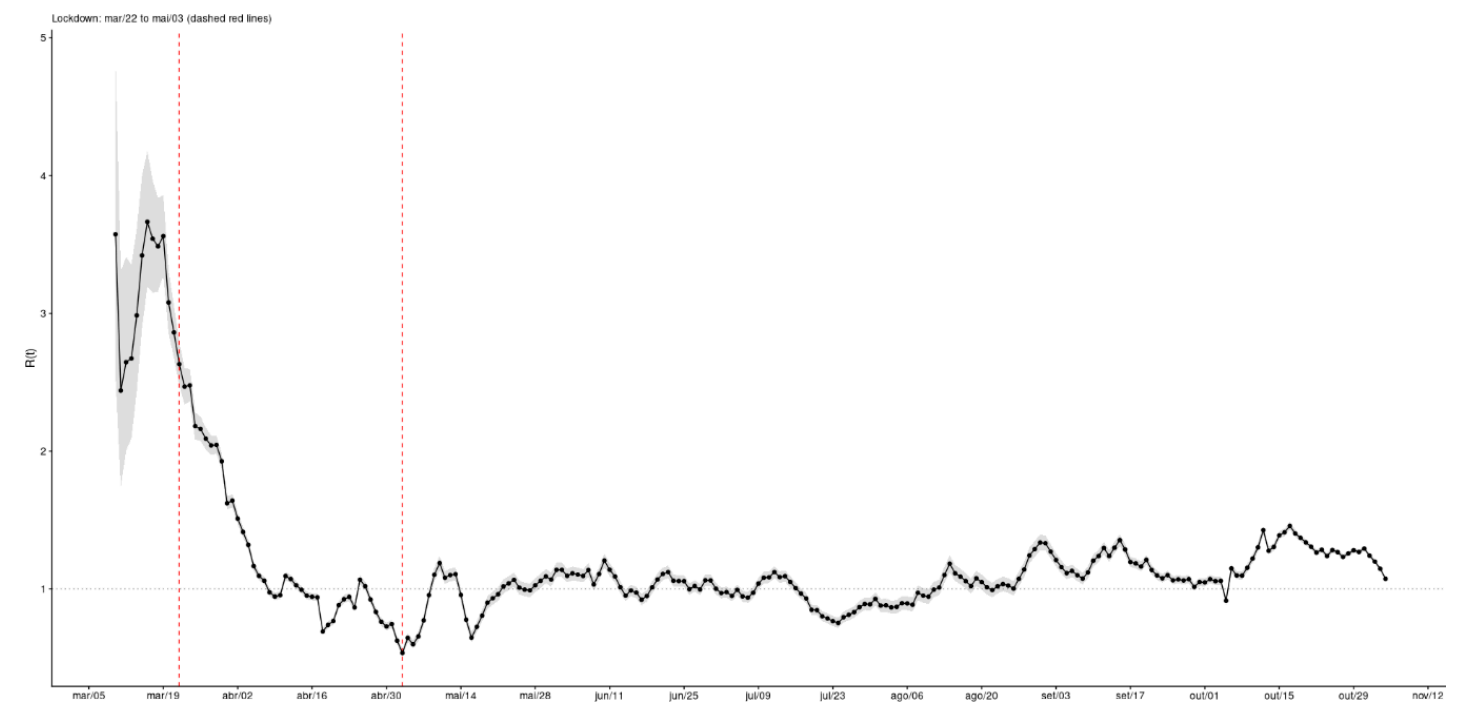

Figure 6. Estimated $R t$ for Portugal.

It is possible to see that the measures adopted between March and April managed to bring the Rt value from a level close to 3 for values around 1. However, after the end of the lockdown (3 May), the values have been close to 1, which means that the COVID-19 pandemic in Portugal has not yet been overcome. Likewise, in other European countries, social distancing and lockdown measures have been adopted, with similar Rt results or even lower results than those observed in Portugal [24].

\section{Discussion}

Considering a Rt less than 1 to be an indicator of "control" of the pandemic, it can be seen that this value was reached only on 8 April in Portugal, i.e., 25 days after the consolidation of the change in the behavior of the mobility patterns of the Portuguese population. Even after this date, the Rt value was very close to 1 , yet it was above this threshold in some moments. This result is like the 21 days found by [25] and the 15-20 days found by [26]. It is noteworthy that these studies use different methodologies to the current study, and a direct comparison would not be entirely adequate. Currently, the cases of COVID-19 have been increasing in Portugal, and a second wave is likely starting. Figure 3 shows that the daily average of cases is already higher than the first wave between March and May 2020. Still, it should be noted that time is a critical factor in combating this pandemic. Less restrictive measures adopted in an early stage of the pandemic can have such a good result, superior to the more restrictive measures adopted in late stages [27].

Additionally, the change in the population's behavior (changepoint) happened before the lockdown. Therefore, this indicator may point out that people's mobility is altered to adapt to the existing pandemic situation even without the end of everyday activities. Still, the places with the lowest flow of people during the monitored period are the transport stations. Nevertheless, this behavior of avoiding public transport creates a challenge for cities in terms of the resumption of economic activities. Additionally, the first place where a second changepoint (Figure 5) was detected was workplaces. This shows that one of the population's priorities after the lockdown was to resume face-to-face economic activities.

Looking at the values since March 2020 (Figures 1 and 2), we see that the values have only returned to baseline for the grocery and pharmacy category. This analysis is essential to understand that post-COVID-19 mobility may not return to this baseline, and the solutions of the future should consider this new behavior of the population. In particular, attention should be paid to public transport, 
one of the most significant negative variation points according to the data collected. The impacts of this change in the behavior of the Portuguese population now are mitigated by the restrictions of the pandemic. However, when the economy reopens there may be a pandemic of private vehicles on the streets.

During the first lockdown in Portugal, some cities imposed restrictions on parks and green spaces; this policy should be reviewed in a second wave. Studies show that these sites have a low risk of contagion and significantly benefit physical and mental health [28,29]. Likewise, it must be understood that COVID-19 has not been eradicated in Portugal, and the second wave of contagions remains on the radar in Europe [30]. Based on Portugal's values, there is such a possibility since the number of confirmed cases so far is not likely to protect a population with herd immunity. Currently, it is essential to define thresholds for the number of new daily cases. Similarly, successful measures used in other countries must be adopted.

Another critical point is that the $R t$ value was obtained based on the number of infected individuals confirmed daily. These numbers may not correspond to the disease's reality, because the number of confirmed infections depends on the number of tests performed [31], and the criteria adopted to test the population were not well explained.

\section{Conclusions}

As the main result of this study, it was observed that the Portuguese population reacted quickly, adopting social distancing, and changing their mobility pattern, even before the government decreed restrictive measures. Still, it took 25 days for an $R t$ value close to 3 to reach values near 1 . Now, it is expected that after the first wave of COVID-19, countries are better prepared for a probable second wave. Notwithstanding, observing the Portuguese population's behavior during that first lockdown, a second intervention of this type to be effective should last between two to four weeks. There are indicators that a second wave of COVID-19 has already started, in this sense, one should continue to monitor the daily cases, as well as the $R t$ value. In this sense, the ideal would be to obtain values for $R t$ below 1 in Portugal.

It was also possible to observe that the sharpest drop occurred in public transport stations. Probably for fear of crowded locations, people sought individualized alternatives. A significant part of the population most likely used the car on their travels. With the re-opening of cities and the economy, this alternative may quickly prove unfeasible. Therefore, there is now a small window to encourage users of active transport. Portugal's infrastructure is not yet prepared for this pattern of sustainable mobility [32], it is recommended that strategies be adopted to make Portuguese cities into cycling cities, mitigating the impact of users' migration to the car.

Another observation was the significant increase in mobility in parks after the softening of lockdown measures. This trend of outdoor activities shows the importance of these spaces for cities. Recent studies point out the importance of these spaces for the population's physical and mental well-being during periods of mobility restrictions.

Finally, we must understand that, for now, life cannot be as it was before the pandemic. Hence, until the discovery of a vaccine, the population and the governments must be prepared for this new normal. For future research, it is recommended to seek a direct relationship between $R t$ and mobility patterns. So far, it is still not entirely clear how social isolation and restrictions on mobility impact the reduction in contagions.

Author Contributions: Conceptualization, A.F. and T.T.; methodology, A.F. and T.T.; software, T.T.; validation, A.F. and T.T.; formal analysis, A.F.; investigation, A.F. and T.T.; resources, A.F. and T.T.; data curation, T.T.; writing —original draft preparation, T.T. and A.F.; writing — review and editing, A.F.; visualization, T.T.; supervision, A.F.; project administration, A.F.; funding acquisition, A.F. and T.T. All authors have read and agreed to the published version of the manuscript.

Funding: This research was funded by the Research Center for Territory, Transports and Environment (CITTA), and also by ACIV. 
Acknowledgments: We would like to thank Google LLC [10] for providing the mobility data of the Portuguese population. We also thank the University of Oxford team for providing updated daily data [14] on the COVID-19 cases.

Conflicts of Interest: The funders had no role in the study; in the collection, analyses, or interpretation of data; in the writing of the manuscript, or in the decision to publish the results.

\section{Appendix A}

The result of the epidemiological modeling is shown in Figure A1. These values were obtained with support from the EpiEstim framework [9].
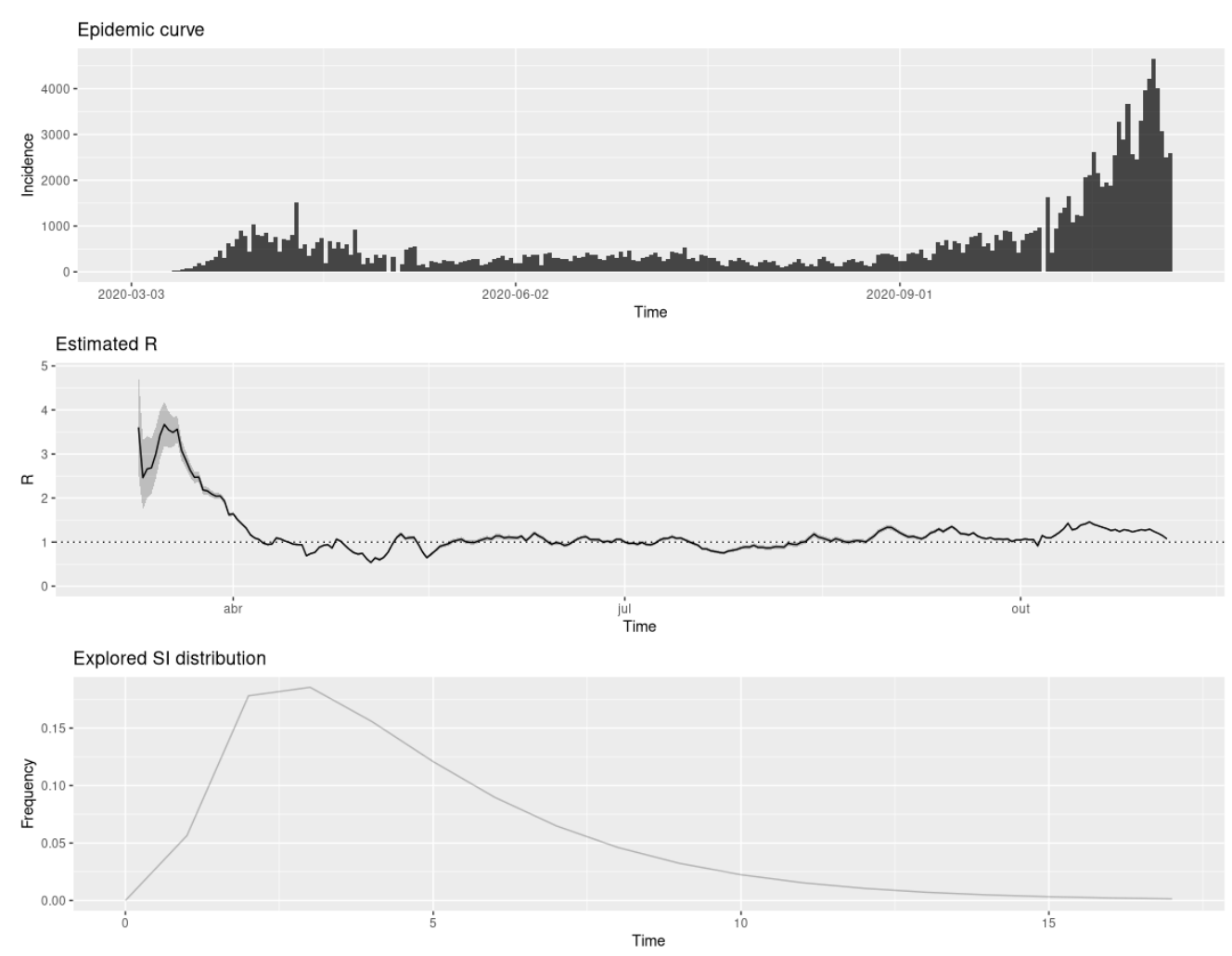

Figure A1. Result of epidemiological modeling.

\section{Appendix B}

The raw data used for the development of this study are presented elsewhere [10,14]. Additionally, the code developed in $\mathrm{R}$ and the processed data and generated images can be accessed in the repository github.com/tamagusko/mobility_patterns_covid19_portugal.

\section{References}

1. Huang, C.; Wang, Y.; Li, X.; Ren, L.; Zhao, J.; Hu, Y.; Zhang, L.; Fan, G.; Xu, J.; Gu, X.; et al. Clinical features of patients infected with 2019 novel coronavirus in Wuhan, China. Lancet 2020, 395, 497-506. [CrossRef]

2. World Health Organization Novel Coronavirus - China 11-fev 2020; World Health Organization: Geneva, Switzerland, 2020.

3. Li, Q.; Guan, X.; Wu, P.; Wang, X.; Zhou, L.; Tong, Y.; Ren, R.; Leung, K.S.M.; Lau, E.H.Y.; Wong, J.Y.; et al. Early Transmission Dynamics in Wuhan, China, of Novel Coronavirus-Infected Pneumonia. N. Engl. J. Med. 2020, 382, 1199-1207. [CrossRef]

4. Spiteri, G.; Fielding, J.; Diercke, M.; Campese, C.; Enouf, V.; Gaymard, A.; Bella, A.; Sognamiglio, P.; Moros, M.J.S.; Riutort, A.N.; et al. First cases of coronavirus disease 2019 (COVID-19) in the WHO European Region, 24 January to 21 February 2020. Eurosurveillance 2020, 25, 2000178. [CrossRef] 
5. Portugal Estamos on: Resposta de Portugal à COVID-19. Available online: https://covid19estamoson.gov.pt (accessed on 25 August 2020).

6. Chinazzi, M.; Davis, J.T.; Ajelli, M.; Gioannini, C.; Litvinova, M.; Merler, S.; Piontti, A.P.Y.; Mu, K.; Rossi, L.; Sun, K.; et al. The effect of travel restrictions on the spread of the 2019 novel coronavirus (COVID-19) outbreak. Science 2020, 368, 395-400. [CrossRef]

7. Haydon, D.T.; Chase-Topping, M.; Shaw, D.J.; Matthews, L.; Friar, J.K.; Wilesmith, J.; Woolhouse, M.E.J. The construction and analysis of epidemic trees with reference to the 2001 UK foot-and-mouth outbreak. Proc. R. Soc. B Biol. Sci. 2003, 270, 121-127. [CrossRef]

8. Wallinga, J. Different Epidemic Curves for Severe Acute Respiratory Syndrome Reveal Similar Impacts of Control Measures. Am. J. Epidemiol. 2004, 160, 509-516. [CrossRef]

9. Cori, A.; Ferguson, N.M.; Fraser, C.; Cauchemez, S. A New Framework and Software to Estimate Time-Varying Reproduction Numbers During Epidemics. Am. J. Epidemiol. 2013, 178, 1505-1512. [CrossRef]

10. Google LLC. Google COVID-19 Community Mobility Reports. Available online: https://www.google.com/ covid19/mobility/ (accessed on 8 May 2020).

11. Rodríguez-Barranco, M.; Rivas-García, L.; Quiles, J.L.; Redondo-Sánchez, D.; Aranda-Ramírez, P.; Llopis-González, J.; Pérez, M.J.S.; Sanchez-Gonzalez, C. The spread of SARS-CoV-2 in Spain: Hygiene habits, sociodemographic profile, mobility patterns and comorbidities. Environ. Res. 2020, 192, 110223. [CrossRef]

12. Data Science for Social Good Portugal Data on the COVID-19 Pandemic in Portugal. Available online: https://github.com/dssg-pt/covid19pt-data (accessed on 4 November 2020).

13. Portugal Governo da República Portuguesa. Available online: https://www.portugal.gov.pt (accessed on 25 August 2020).

14. Roser, M.; Ritchie, H.; Ortiz-Ospina, E.; Hasell, J. Coronavirus Pandemic (COVID-19). Available online: https://ourworldindata.org/coronavirus (accessed on 10 August 2020).

15. Aktay, A.; Bavadekar, S.; Cossoul, G.; Davis, J.; Desfontaines, D.; Fabrikant, A.; Gabrilovich, E.; Gadepalli, K.; Gipson, B.; Guevara, M.; et al. Google COVID-19 Community Mobility Reports: Anonymization Process Description (version 1.0). arXiv 2020, arXiv:2004.04145.

16. Jenelius, E.; Cebecauer, M. Impacts of COVID-19 on public transport ridership in Sweden: Analysis of ticket validations, sales and passenger counts. Transp. Res. Interdiscip. Perspect. 2020, 8, 100242. [CrossRef]

17. RStudio Team. RStudio: Integrated Development for R; RStudio, Inc.: Boston, MA, USA, 2020.

18. R Core Team. R: A Language and Environment for Statistical Computing; R Core Team: Vienna, Austria, 2017.

19. Killick, R.; Eckley, I.A. Changepoint: An R Package for Changepoint Analysis. J. Stat. Softw. 2014, 58, 1-19. [CrossRef]

20. Scott, A.A.J.; Knott, M. A Cluster Analysis Method for Grouping Means in the Analysis of Variance Published by: International Biometric Society Stable. Biometrics 1974, 30, 507-512. [CrossRef]

21. Killick, R.; Fearnhead, P.; Eckley, I.A. Optimal Detection of Changepoints with a Linear Computational Cost. J. Am. Stat. Assoc. 2012, 107, 1590-1598. [CrossRef]

22. Nishiura, H.; Linton, N.M.; Akhmetzhanov, A.R. Serial interval of novel coronavirus (COVID-19) infections. Int. J. Infect. Dis. 2020, 93, 284-286. [CrossRef]

23. WHO. Considerations for Quarantine of Individuals in the Context of Containment for Coronavirus Disease (COVID-19); WHO: Geneva, Switzerland, 2020; pp. 3-5.

24. Flaxman, S.; Mishra, S.; Gandy, A.; Unwin, H.J.T.; Mellan, T.A.; Coupland, H.; Whittaker, C.; Zhu, H.; Berah, T.; Eaton, J.W.; et al. Estimating the effects of non-pharmaceutical interventions on COVID-19 in Europe. Nat. Cell Biol. 2020, 584, 257-261. [CrossRef]

25. Cartenì, A.; Di Francesco, L.; Martino, M. How mobility habits influenced the spread of the COVID-19 pandemic: Results from the Italian case study. Sci. Total Environ. 2020, 741, 140489. [CrossRef]

26. Gondauri, D.; Batiashvili, M. The Study of the Effects of Mobility Trends on the Statistical Models of the COVID-19 Virus Spreading. Electron. J. Gen. Med. 2020, 17, em243. [CrossRef]

27. Loewenthal, G.; Abadi, S.; Avram, O.; Halabi, K.; Ecker, N.; Nagar, N.; Mayrose, I.; Pupko, T. COVID-19 pandemic-related lockdown: Response time is more important than its strictness. EMBO Mol. Med. 2020, 12, 1-8. [CrossRef]

28. Slater, S.J.; Christiana, R.W.; Gustat, J. Recommendations for Keeping Parks and Green Space Accessible for Mental and Physical Health during COVID-19 and Other Pandemics. Prev. Chronic Dis. 2020, 17, E59. [CrossRef] 
29. Venter, Z.S.; Barton, D.N.; Gundersen, V.; Figari, H.; Nowell, M. Urban nature in a time of crisis: Recreational use of green space increases during the COVID-19 outbreak in Oslo, Norway. Environ. Res. Lett. 2020, 15, 104075. [CrossRef]

30. Wise, J. Covid-19: Risk of second wave is very real, say researchers. BMJ 2020, 369, m2294. [CrossRef]

31. Gopalan, A.; Tyagi, H. How Reliable are Test Numbers for Revealing the COVID-19 Ground Truth and Applying Interventions? J. Indian Inst. Sci. 2020, 1-22. [CrossRef]

32. Silva, C.; Teixeira, J.; Proença, A. Revealing the Cycling Potential of Starter Cycling Cities. Transp. Res. Procedia 2019, 41, 637-654. [CrossRef]

Publisher's Note: MDPI stays neutral with regard to jurisdictional claims in published maps and institutional affiliations.

(C) 2020 by the authors. Licensee MDPI, Basel, Switzerland. This article is an open access article distributed under the terms and conditions of the Creative Commons Attribution (CC BY) license (http://creativecommons.org/licenses/by/4.0/). 